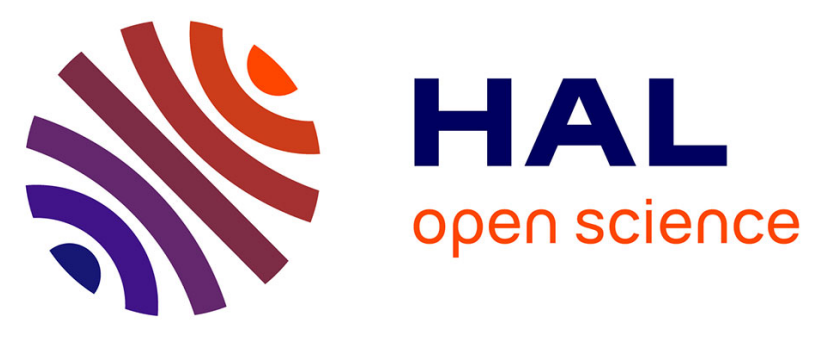

\title{
Modeling the Reactivity of Aged Paper with Aminoalkylalkoxysilanes as Strengthening and Deacidification Agents
}

Nathan Ferrandin-Schoffel, Mohamed Haouas, Charlotte Martineau-Corcos, Odile Fichet, Anne-Laurence Dupont

\section{To cite this version:}

Nathan Ferrandin-Schoffel, Mohamed Haouas, Charlotte Martineau-Corcos, Odile Fichet, AnneLaurence Dupont. Modeling the Reactivity of Aged Paper with Aminoalkylalkoxysilanes as Strengthening and Deacidification Agents. ACS Applied Polymer Materials, 2020, 2 (5), pp.1943-1953. 10.1021/acsapm.0c00132 . hal-02887844v2

\section{HAL Id: hal-02887844 \\ https://hal.science/hal-02887844v2}

Submitted on 27 Nov 2020

HAL is a multi-disciplinary open access archive for the deposit and dissemination of scientific research documents, whether they are published or not. The documents may come from teaching and research institutions in France or abroad, or from public or private research centers.
L'archive ouverte pluridisciplinaire HAL, est destinée au dépôt et à la diffusion de documents scientifiques de niveau recherche, publiés ou non, émanant des établissements d'enseignement et de recherche français ou étrangers, des laboratoires publics ou privés. 


\title{
Modeling the reactivity of aged paper with aminoalkylalkoxysilanes as strengthening and deacidification agents
}

\author{
Nathan Ferrandin-Schoffel ${ }^{1,2 *}$, Mohamed Haouas ${ }^{3}$, Charlotte Martineau-Corcos ${ }^{3}$, Odile Fichet ${ }^{2}$, Anne- \\ Laurence Dupont ${ }^{1 *}$ \\ ${ }^{1}$ Centre de Recherche sur la Conservation des Collections (CRC, CNRS USR 3224), Muséum National d'Histoire \\ Naturelle, 36 rue Geoffroy St Hilaire 75005 Paris, France \\ ${ }^{2}$ Laboratoire de Physicochimie des Polymères et des Interfaces (LPPI, EA 2528), Institut des Matériaux, Université \\ de Cergy-Pontoise, 5 mail Gay-Lussac, Neuville sur Oise, 95031 Cergy-Pontoise cedex, France \\ ${ }^{3}$ Institut Lavoisier de Versailles (ILV, UMR 8180), Université de Versailles Saint-Quentin, 45 avenue des Etats- \\ Unis, 78035 Versailles, France \\ *Corresponding authors: anne-laurence.dupont@mnhn.fr,nathan.ferrandin-schoffel@mnhn.fr
}

Keywords Aminoalkylalkoxysilane - Cellulose - Lignin - Modelling - Nuclear magnetic resonance Schiff base

\begin{abstract}
Aminoalkylalkoxysilane (AAAS) flexible copolymer networks can be used to deacidify and strengthen paper in a one-step operation. The treatment is versatile and can be tailored to convey a balanced combination of tensile strength and pliability to degraded paper from library and archives collections. The treatment efficiency on bleached pulp and rag or cotton paper has been shown to be always suitable. It is however challenged when the paper contains lignin and is very degraded. The reasons for this are still poorly understood. Indeed, the reactions at room temperature of AAAS with the biopolymers in paper are difficult to characterize. In this work, the hydrolysis and polycondensation reactions of an AAAS monomer (3-aminopropylmethyldiethoxysilane, AM) were closely examined, and the interactions with lignin and cellulose were studied using a modelling approach. To this end, several model organic molecules were used to reproduce the main functional groups of cellulose and lignin. The reactions with AM were studied with ATR-FTIR and NMR using ${ }^{1} \mathrm{H},{ }^{13} \mathrm{C},{ }^{29} \mathrm{Si}$, and ${ }^{1} \mathrm{H}-\mathrm{X}\left(\mathrm{X}={ }^{13} \mathrm{C},{ }^{15} \mathrm{~N}\right.$, or ${ }^{29} \mathrm{Si}$ ) heteronuclear multiple bond correlation (HMBC). The results showed that carbonyl and carboxyl groups react with the amine and silicate moieties of AM. These results are paralleled with the physicochemical properties of three oxidized and brittle newsprint papers to explain the variable degree of strengthening observed upon AAAS treatment.
\end{abstract}

A Supplementary Material file is available. It contains supporting information to the article, including ATR-FTIR spectra (J1, J2 and J3, vanillin and AM/vanillin, vanillic acid and AM/vanillic acid, pbenzoquinone and AM/p-benzoquinone), ${ }^{13} C N M R$ spectra (AM, methyl- $\beta$-D-glucopyranoside (MGPO), and $A M / M G P O)$ and ${ }^{1} H$ NMR spectra (p-benzoquinone and AM/p-benzoquinone). 


\section{Introduction}

Paper slowly decays with time. Cellulose, the main biopolymer in paper, undergoes acid-catalyzed hydrolysis that decreases the degree of polymerization (DP), which in turn progressively leads to loss in mechanical resistance of the paper. In addition, the natural slow formation of carbonyl compounds among other degradation by-products increases the acidity. Late $19^{\text {th }}$ - early $20^{\text {th }}$ century lignocellulosic paper collections, especially newsprint paper of mediocre quality, degrade faster than more durable paper, and can become extremely brittle. As a preventive measure, mass treatments have been developed for the deacidification of libraries and archives collections. ${ }^{1-4}$ Nevertheless, these processes do not provide a comprehensive solution for the most degraded (acidic and brittle) documents, which additionally, would need to be mechanically strengthened. In order to overcome this problem, one-pot treatments based on the use of aminoalkylalkoxysilanes (AAAS), imparting simultaneous deacidification and strengthening to cellulosic objects, have been proposed. ${ }^{5-11}$

Previously published results showed the full potential of AAAS treatments in organic solvent phase, including fungistatic properties of the treated documents. ${ }^{12}$ At the laboratory or the conservation workshop scale, the treatment can be applied by spray or by immersion, undiluted or diluted in an organic solvent, usually hexamethyldisiloxane (HMDSO). At the "mass" industrial scale, the use of a nonprotic solvent such as HMDSO is recommended to avoid the bleeding of water-soluble inks, dyes and binders, fiber swelling, and also to shorten the drying time. ${ }^{1,8,13}$ More recently, flexible copolymer networks (co-AAAS) have been studied, with the aim of conveying a balanced combination of tensile strength and pliability to very degraded paper. ${ }^{11}$ The treatment is versatile as its formulation can easily be modified by changing the monomers, their proportions and their concentration. Efficient deacidification and increase in the tensile breaking length has been obtained, ${ }^{11,14}$ but an increase in folding endurance increase was less easily achieved, ${ }^{14,15}$ and slight yellowing was sometimes observed..$^{9,10}$ The interactions taking place between the AAAS and the paper are still unclear. The aim of this research was thus to investigate these interactions. It has been previously suggested that the amine group, which drives the deacidification, also favors the adsorption of the AAAS in the cellulosic material and forms hydrogen bonds. ${ }^{8-10}$ To account for the observed slight yellowing of the treated papers, the formation of Schiff bases through covalent bonding between the amine groups and carbonyl groups in oxidized paper was hypothethised. ${ }^{5,6,9,10}$ On the other hand, strengthening, which is thought to be imparted by the in situ polymerization, thus depends on the DP of the AAAS, i.e. on their ability to hydrolyze with the water naturally absorbed in the fibers in the first step of the reaction (eq. 1), and to subsequently condensate at room temperature. The condensation step can be hydrolytically-driven (eq. 2 ) in which case water is regenerated ${ }^{16}$ or alcohol-driven (eq. 3). 
- Hydrolysis:

$-\mathrm{Si}_{1}^{\mathrm{S}-\mathrm{OR}}+\mathrm{H}_{2} \mathrm{O} \longrightarrow-\frac{1}{\mathrm{Si}-\mathrm{OH}}+\mathrm{ROH}$

- Hydrolytic polycondensation:

$-\stackrel{\mathrm{Si}-\mathrm{OH}}{\mid}+\underset{\mathrm{HO}-\mathrm{Si}-}{\mid} \longrightarrow-\underset{\mid}{\mathrm{Si}-\mathrm{O}-\mathrm{Si}-}+\mathrm{H}_{2} \mathrm{O}$

- Alcoholic polycondensation:

$-\stackrel{\mathrm{Si}-\mathrm{OH}}{\mid}+\underset{\mathrm{RO}-\mathrm{Si}}{\mathrm{I}} \longrightarrow-\underset{\mathrm{Si}-\mathrm{O}-\mathrm{Si}-}{\mid}+\mathrm{ROH}$

In acidic conditions and at room temperature the hydrolysis of alkoxysilanes is catalyzed, whereas the condensation is slower and can take up to several months. ${ }^{17,18}$ In contrast, it has been shown that both the hydrolysis and the polycondensation steps are catalyzed in alkaline conditions. ${ }^{17-19}$ Hence, these reactions can be catalyzed by the amine functions on the AAAS molecules. ${ }^{18,19}$ Acids continuously produced during the natural aging of paper would partly neutralize these bases in situ, gradually leading to near-neutral conditions and subsequently slower polycondensation kinetics. Likewise, the proposed formation of covalent bonds between the amines of the AAAS and carbonyl groups from the degraded paper could in all likelihood limit the size of the polymer. As another induced drawback, the alkaline reserve brought by the amine group would be lower than expected.

Previously, it has been suggested that several constituents of the paper were likely to affect the treatment's efficiency. Among them, alum-rosin sizing ${ }^{14,15}$ and groundwood pulp, ${ }^{10,15}$ which are present in significant amount in early newsprint paper made from unpurified wood. Mechanical pulp from softwood typically contains between 25 and $31 \mathrm{wt} \%$ of lignin in the near-native form. ${ }^{20}$ Lignin is an amorphous tridimensional biopolymer largely responsible for the paper acidity and yellowing upon aging. ${ }^{21}$ More generally, reactions that occur at room temperature in the paper between AAAS and the biomacromolecules, i.e. cellulose, hemicelluloses and lignin, are difficult to characterize and are still not fully understood. For example, most routine spectroscopic techniques do not have enough resolving power to characterize precisely carbonyl groups in-situ. ${ }^{22}$ In this work, we identified possible reactions taking place between the AAAS and the paper, which could explain the variable degree of strengthening obtained with different papers. To this purpose, a model study was undertaken. Several organic molecules were chosen as their structure encompassed the main functional groups of cellulose and lignin. They were mixed to 3-aminopropylmethyldiethoxysilane, henceforth called AM, a bifunctional AAAS that condensates into a linear polysiloxane. Fourier-transform infrared (FTIR) and liquid-state Nuclear Magnetic Resonance (NMR) spectroscopies were used to study the molecular interactions between AM and the model organic molecules. Previous studies showed the capacity of AM to penetrate in the fibers network and in situ polymerize, yielding an increase in the mechanical properties, both in 
undegraded and degraded paper. ${ }^{8,9,11,14,15}$ The study with the model compounds was thus paralleled with the results of the mechanical strengthening of three newsprint papers in various states of degradation, made of lignin-rich or lignin-free pulp mixtures.

\section{Experimental}

\subsection{Paper samples}

Naturally aged lignocellulosic newsprint paper was used. Three copies (called J1, J2 and J3) of the "Journal des Fabricants de Sucre", a newspaper published through late $19^{\text {th }}$ - early $20^{\text {th }}$ century, were provided by the Bibliothèque Nationale de France. Their constituents and some of their physicochemical properties are summarized in Table 1.

The fibers and the pulp of the three newsprint papers were determined by microscopic examination and histological staining with Herzberg, Lofton-Merritt and Graff-C solutions. ${ }^{23}$

Microchemical test for rosin ${ }^{24}$ was performed to check for alum-rosin sizing. Kaolin fillers in the papers were identified by ATR-FTIR (Nicolet 6700 spectrophotometer). This clay mineral contains large amounts of kaolinite, an aluminosilicate which displays two typical absorption bands around $3690 \mathrm{~cm}^{-1}$ and $3620 \mathrm{~cm}^{-1}$ (O-H stretch) ${ }^{25}$ (Figure S1 in the Supporting Information file). The ash content enabled to quantify the amount of mineral fillers in the papers (TAPPI T211 om-02). Two measurements were done per paper.

Table 1. Main constituents and characteristics of the newsprint papers.

\begin{tabular}{llll}
\hline & J1 & J2 & J3 \\
\hline Date of publication & 1911 & 1920 & 1923 \\
Pulp & BSP, softwood & $\begin{array}{l}\text { GP/USP/BSP, softwood, } \\
\text { trace of straw }\end{array}$ & $\begin{array}{l}\text { GP/USP/BSP, softwood, } \\
\text { trace of straw }\end{array}$ \\
& & 7.6 & 16.3 \\
Ash content $\left(\%_{\mathrm{w}}\right)$ & 17.8 & 49 & 52 \\
Grammage $\left(\mathrm{g} \mathrm{m}^{-2}\right)$ & 57 & 64 & 63 \\
Thickness $(\mu \mathrm{m})$ & 59 & &
\end{tabular}

BSP: bleached sulfite pulp. GP: groundwood pulp. USP: unbleached sulfite pulp.

\subsection{Chemicals}

\subsubsection{Aminoalkylalkoxysilanes}

AM (97\%), 3-aminopropyltriethoxysilane (AP) (>98\%) and $N$-(2-aminoethyl)-3aminopropylmethyldimethoxysilane (DIA) (97\%) were purchased from ABCR (Gelest, France) and used as received. 


\subsubsection{Model compounds}

D-glucose (LABOSI) and methyl- $\beta$-D-glucopyranoside (MGPO) (>99\%, Sigma-Aldrich) were used as molecular models for cellulose. 4-hydroxy-3-methoxybenzaldehyde (vanillin) (99\%, Sigma), 4hydroxy-3-methoxybenzoic acid (vanillic acid) (97\%, Sigma-Aldrich), 4-hydroxy-3-methoxybenzy1 alcohol (vanillyl alcohol) (98\%, Sigma-Aldrich), p-benzoquinone (98\%, Acros Organics), 4methoxyphenol (mequinol) (99\%, Aldrich), methoxybenzene (anisole) ( $\geq 99 \%$, Aldrich), phenol $(\geq$ 99\%, Acros Organics) and cyclohexanol (99\%, Aldrich) were used as model molecules for lignin.

\subsection{Paper treatment}

AP/DIA (5/95) (wt/wt) mixture was directly sprayed on the paper samples with an airbrush (Airbrush Hobby Kit, Silverline). This formulation was previously established as the most efficient for the treatment of a sample from the same newspaper collection. ${ }^{14}$ The uptake was calculated as follows:

$$
\mathrm{UP}(w \mathrm{t} \%)=\frac{\left(\mathrm{w}_{\mathrm{f}}-\mathrm{w}_{\mathrm{i}}\right)}{\mathrm{w}_{\mathrm{i}}} \times 100
$$

where $\mathrm{w}_{\mathrm{i}}$ and $\mathrm{w}_{\mathrm{f}}$ are the paper weight before and after treatment, respectively. Each sample was dried for at least $3 \mathrm{~h}$ at room temperature, conditioned at $23{ }^{\circ} \mathrm{C}$ and $50 \% \mathrm{RH}$ for a minimum of $24 \mathrm{~h}$ (TAPPI T402 sp-03) and weighted.

For relevant comparisons, the paper samples were treated so as to obtain similar uptakes $(9 \pm 0.5 \%)$.

\subsection{Physico-chemical characterizations}

The cold extract $\mathrm{pH}$ was measured with a $\mathrm{pH}-$ meter (Mettler Toledo MA235) according to TAPPI T509 om-02 standard adapted to a sample mass of $100 \mathrm{mg}$. Three repeat measurements were carried out per paper.

Prior to the mechanical testing measurements (tensile strength and folding endurance) the samples were conditioned according to TAPPI T402 sp-03. Tensile Breaking Length (BL) and Elongation at Break (EB) were measured with an Adamel Lhomargy instrument (DY-20N) according to TAPPI T494 om-01 standard. BL ( $\mathrm{km})$ is the limiting length of a strip of paper of uniform width, beyond which, if such a strip were suspended by one end, it would break of its own weight. It is related to the tensile strength $\mathrm{T}\left(\mathrm{kN} \mathrm{m}^{-1}\right)$ according to:

$$
\mathrm{BL}=102 \times \frac{\mathrm{T}}{\mathrm{R}}
$$

where $\mathrm{R}$ is the grammage of the paper $\left(\mathrm{g} \mathrm{m}^{-2}\right)$. 
Folding endurance (FE) was determined with a Tinius Olsen instrument (applied force: $500 \mathrm{~g}$ ) according to TAPPI T511 om-02 standard. Ten measurements were done per sample in the machine direction of the sheets.

The ${ }^{1} \mathrm{H},{ }^{13} \mathrm{C},{ }^{29} \mathrm{Si}$, and ${ }^{1} \mathrm{H}-\mathrm{X}\left(\mathrm{X}={ }^{13} \mathrm{C},{ }^{15} \mathrm{~N}\right.$, or $\left.{ }^{29} \mathrm{Si}\right)$ heteronuclear multiple bond correlation (HMBC) spectra were collected at room temperature for about $0.6 \mathrm{~mL}$ of the prepared solutions in deuterated dimethyl sulfoxide (DMSO- $d_{6}$ ) by using a $\mathrm{H} / \mathrm{X}$ broadband probe with $\mathrm{Z}$ gradient installed in an Avance $400 \mathrm{NMR}$ spectrometer. The ${ }^{1} \mathrm{H}$ spectra were recorded by using Larmor frequency at $400.13 \mathrm{MHz}$. A standard one-pulse sequence employing a 30-degree proton pulse was used. The spectral width and acquisition time were $5 \mathrm{kHz}$ and $3 \mathrm{~s}$, respectively. The relaxation delay was $1 \mathrm{~s}$, and eight transients were signal-averaged. The ${ }^{13} \mathrm{C}$ NMR spectra were recorded at $100.62 \mathrm{MHz}$ by using a power gated decoupling sequence with a 90-degree carbon pulse. The spectral width, acquisition time and recycle delay were $25 \mathrm{kHz}, 1 \mathrm{~s}$ and $5 \mathrm{~s}$, respectively. A total of 4096 transients were signal-averaged for a total measurement time of $7 \mathrm{~h}$. The ${ }^{29} \mathrm{Si}$ NMR spectra were acquired at $79.49 \mathrm{MHz}$. The spectral width, acquisition time, and recycle delay were $6 \mathrm{kHz}, 1.3 \mathrm{~s}$, and $12 \mathrm{~s}$, respectively. The 90 -degree pulse length was $12.7 \mu$ and 4096 transients were signal-averaged. In the ${ }^{1} \mathrm{H}-{ }^{13} \mathrm{C} \mathrm{HMBC}$ experiments, the proton dimension was acquired by using 4096 data points, $5 \mathrm{kHz}$ spectralwidth, 32 scans, and $1 \mathrm{~s}$ recycle delay. The ${ }^{13} \mathrm{C}$ dimension was recorded by using $256 \mathrm{t} 1$ increments, and $25 \mathrm{kHz}$ spectral width. To collect ${ }^{1} \mathrm{H}-$ ${ }^{15} \mathrm{~N}$ HMBC spectra of the solutions, the spectrometer was operated at $40.55 \mathrm{MHz}$ for ${ }^{15} \mathrm{~N}$. The spectral width for the nitrogen dimension was $20 \mathrm{kHz}$, and $44 \mathrm{t} 1$ increments were used. For the proton dimension, the acquisition time and the spectral width were $0.4 \mathrm{~s}$ and $5 \mathrm{kHz}$, respectively. The spectrum was acquired with 512 scans and 2 s recycle delay. For the ${ }^{1} \mathrm{H}-{ }^{29} \mathrm{Si} \mathrm{HMBC}$ experiments, the proton dimension was acquired by using 8192 data points, $5 \mathrm{kHz}$ spectral width, 64 scans, and $1 \mathrm{~s}$ recycle delay. The ${ }^{29} \mathrm{Si}$ dimension was recorded by using $100 \mathrm{t} 1 \mathrm{increments}$, and $2.5 \mathrm{kHz}$ spectral width. The ${ }^{1} \mathrm{H},{ }^{13} \mathrm{C}$, and ${ }^{29} \mathrm{Si}$ spectra were referenced to tetramethylsilane (TMS) at $0 \mathrm{ppm}$, whereas ${ }^{15} \mathrm{~N}$ spectra were referenced to nitromethane at $0 \mathrm{ppm}$.

A kinetic study of the model mixtures was performed by ${ }^{1} \mathrm{H}$ NMR at $\mathrm{t}_{0}$ (i.e. time when the NMR solvent was added) and 7 days later with a Bruker Avance DPX-250 (250 MHz).

FTIR spectra of the newsprint papers and the model compounds in solution were obtained with a Nicolet 6700 spectrophotometer, equipped with a diamond Smart Endurance ATR macro-system scanning from 500 to $4000 \mathrm{~cm}^{-1}$. For each spectrum, 64 scans were recorded, with a resolution of $4 \mathrm{~cm}^{-}$

${ }^{1}$. Each model compound was dissolved in dimethyl sulfoxide (DMSO). For each of the model mixtures, a spectrum was obtained at $\mathrm{t}_{0}$ and 7 days later.

\section{Results and discussion}

First, a study of the chemical and mechanical properties of the three newsprint papers treated with AAAS copolymers was undertaken. 


\subsection{Physico-chemical measurements}

As expected, each of the initially acidic newsprint papers was deacidified by the treatment ( $\mathrm{pH}$ above 7.5) (Table 2). All papers also showed an increase in tensile strength, indicating improved inter and intra-fiber bonding via the breaking length (BL) and deformability through the elongation at break (EB). It was noted that a larger increase of $\mathrm{BL}(\mathrm{J} 2:+40 \%, \mathrm{~J} 1:+25 \%, \mathrm{~J} 3:+26 \%)$ went along with a slightly smaller increase in EB (J2: $+13 \%, \mathrm{~J} 1:+20 \%, \mathrm{~J} 3:+25 \%)$.

Table 2. $\mathrm{pH}, \mathrm{BL}$ and $\mathrm{EB}$ of the untreated and treated (AP/DIA 5/95) newsprint papers.

\begin{tabular}{lllll}
\hline & & J1 & J2 & J3 \\
\hline \multirow{2}{*}{$\mathrm{pH}$} & Untreated & $4.97 \pm 0.03$ & $4.53 \pm 0.06$ & $4.84 \pm 0.03$ \\
& Treated & $7.76 \pm 0.01$ & $7.58 \pm 0.01$ & $7.57 \pm 0.10$ \\
\multirow{2}{*}{ BL $(\mathrm{km})$} & Untreated & $2.09 \pm 0.27$ & $2.76 \pm 0.26$ & $2.70 \pm 0.45$ \\
& Treated & $2.61 \pm 0.30$ & $3.87 \pm 0.46$ & $3.40 \pm 0.41$ \\
\multirow{2}{*}{ EB $(\%)$} & Untreated & $0.94 \pm 0.15$ & $1.02 \pm 0.15$ & $1.06 \pm 0.17$ \\
& Treated & $1.13 \pm 0.15$ & $1.15 \pm 0.14$ & $1.33 \pm 0.11$ \\
\hline
\end{tabular}

Figure 1 shows the FE of the papers. J1 and J2 are very brittle, with an initial FE below 10 double folds $(\mathrm{N}<10)$ whereas $\mathrm{J} 3$ is relatively less brittle $(\mathrm{N} \approx 22)$. The papers reacted differently to the treatment, exhibiting a variable degree of strengthening. It was previously suggested that the initial $\mathrm{FE}$ impacted the reinforcement efficiency, with a critical value $(\mathrm{N} \approx 10)$ below which the sample is hardly reinforced. ${ }^{10,14}$ This limitation was indeed observed for J2, but in contrast, J1 was strengthened after treatment $(\mathrm{N} \approx 27)$. This result is consistent with the higher elongation at break imparted by the treatment to $\mathrm{J} 1$ than to $\mathrm{J} 2$.

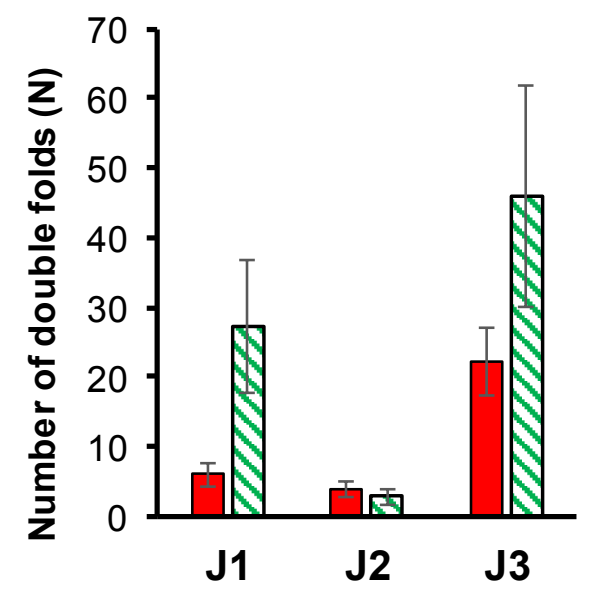

Figure 1. FE of J1, J2 and J3, before (red filled bars) and after (green hatched bars) treatment with AP/DIA (5/95). 
The tests showed that, despite a different pulp composition, all three papers contain alum-rosin sizing and kaolin fillers and have similar grammage and thickness (Table 1). Lignin was evidenced in J2 and J3 using FTIR, by the absorption bands around $1590 \mathrm{~cm}^{-1}$ (aryl ring symmetric stretching) and $1510 \mathrm{~cm}^{-}$ ${ }^{1}$ (aryl ring asymmetric stretching). ${ }^{26,27} \mathrm{~J} 1$ does not contain lignin, as shown by the absence of these absorption bands on the FTIR spectrum (Figure S1 in the Supporting Information file). Another difference between the three papers appeared to be the proportion of kaolin, which was much lower for $\mathrm{J} 2\left(7.6 \%_{\mathrm{w}}\right)$ than for J1 $\left(17.8 \%_{\mathrm{w}}\right)$ and J3 $\left(16.3 \%_{\mathrm{w}}\right)$ (Table 1). However, previous research showed that the quantity of fillers had no appreciable impact on the treatment efficiency. ${ }^{15}$ Subsequently, it seems that the presence of lignin (from the groundwood pulp) could be a factor that most likely hampers the folding endurance improvement of the most brittle papers. This hypothesis was supported in previous research by the fact that an aged cotton paper, made of cellulose $100 \%$, with a folding endurance of 20 double folds, could be strengthened. ${ }^{14}$ Thus, this raises the question of the chemical reactions possibly occurring between the AAAS, on the one hand, and cellulose and lignin, on the other hand that could account for the observed results. This interrogation prompted the need of modeling the system using simple molecules in the present research.

\subsection{Model carbohydrate compounds}

Cellulose is a polymer made of $\beta$-D-glucose bonded to each other with acetal functional groups linkages. A glycosidic bond links the equatorial $-\mathrm{OH}$ of the carbon $\mathrm{C}_{4}$ from a unit to the carbon $\mathrm{C}_{1}$ of the neighboring unit (Figure S2a in the Supporting Information file). In nature, the degree of polymerization (DP) of cellulose ranges from the hundreds to the thousands. ${ }^{28} \mathrm{D}$-glucose is a trivial molecular model of the cellulose monomer. D-glucose used in this research contains both $\alpha$ and $\beta$ anomers, since pure $\beta$-D-glucose is not commercially available.

The other most abundant carbohydrate biopolymers in pulp are hemicelluloses. Unbleached and bleached woodpulp papers contain significant amounts of hemicelluloses. ${ }^{29}$ They are heteropolysaccharides that act as a cohesive matrix between the cellulose microfibrils. ${ }^{30}$ They are made of linear and branched chains of different sugar monomers. ${ }^{29}$ The type of hemicelluloses and their proportion in the pulp depend on the origin of the fibers and on the pulping process. Their average DPs are low (about 200 for the softwood fibers ${ }^{29,31}$ ) compared to cellulose. Although glucose is a recurring repeat unit in most hemicelluloses, other sugars are also present as for instance, galactose and mannose in galactoglucomannan. The latter are abundant in softwood fibers. ${ }^{28} \mathrm{D}$-glucose is the only saccharide monomer studied here. Until further investigation, a similar reactivity of the other sugar units will be assumed.

In order to study the interaction between the AAAS and cellulose, an AM/D-glucose equimolar mixture was dissolved in DMSO- $d_{6}$, and the $2 \mathrm{D}{ }^{1} \mathrm{H}-{ }^{15} \mathrm{~N}$ HMBC NMR spectrum was recorded (Figure 2a). It showed a signal at about $-354 \mathrm{ppm}$, corresponding to the nitrogen of unreacted AM, in addition 
to new signals at about $-337 \mathrm{ppm}$ and $-326 \mathrm{ppm}$. These two new peaks were related to the nitrogen atoms $\mathrm{N}(\alpha)$ of an $\alpha$-glycosylamine and $\mathrm{N}(\beta)$ of a $\beta$-glycosylamine, respectively. The hydrogens $\mathrm{H}\left(\alpha-2^{\prime}\right)(3.26$ ppm) and $\mathrm{H}\left(\beta-2^{\prime}\right)$ (2.86 ppm) both correlate through ${ }^{3} \mathrm{~J}$ couplings with the nitrogen atom of AM, which evidences the formation of a covalent bond between the amine group and D-glucose. In the experimental conditions, ${ }^{3} \mathbf{J}$ couplings showed stronger intensities than ${ }^{2} \mathbf{J}$ couplings, which may explain why a ${ }^{2} \mathbf{J}$ coupling was not detected between $\mathrm{N}(\alpha)$ and $\mathrm{H}\left(\alpha-1^{\prime}\right)$ (4.28 ppm), and was only moderately visible between $\mathrm{N}(\beta)$ and $\mathrm{H}\left(\beta-1^{\prime}\right)$ (3.62 ppm). The evidence of covalent bond formation is also provided by the $2 \mathrm{D}{ }^{1} \mathrm{H}-{ }^{13} \mathrm{C}$ HMBC NMR spectrum with the ${ }^{3} \mathrm{~J}$ couplings between $\mathrm{C}(\alpha-\mathrm{a})(50.2 \mathrm{ppm})$ and $\mathrm{H}(\alpha-1$ ') , and between $\mathrm{C}\left(\beta\right.$-a) (49.8 ppm) and $\mathrm{H}\left(\beta-1^{\prime}\right)$ (Figure $2 \mathrm{~b}$ ).

The covalent bond between the amine of AM and the anomeric carbon of D-glucose was attributed to a Maillard reaction (Figure 3). This reaction involves an intermediate, which is the open ring structure of D-glucose, with an aldehyde group on $\mathrm{C}_{1}$. The first step of the reaction mechanism is the formation of a Schiff base, through a condensation reaction which releases water. Thereafter, glycosylamine is produced by Amadori rearrangement. Such addition of primary amines on glucose units has been reported in the literature..$^{32,33}$
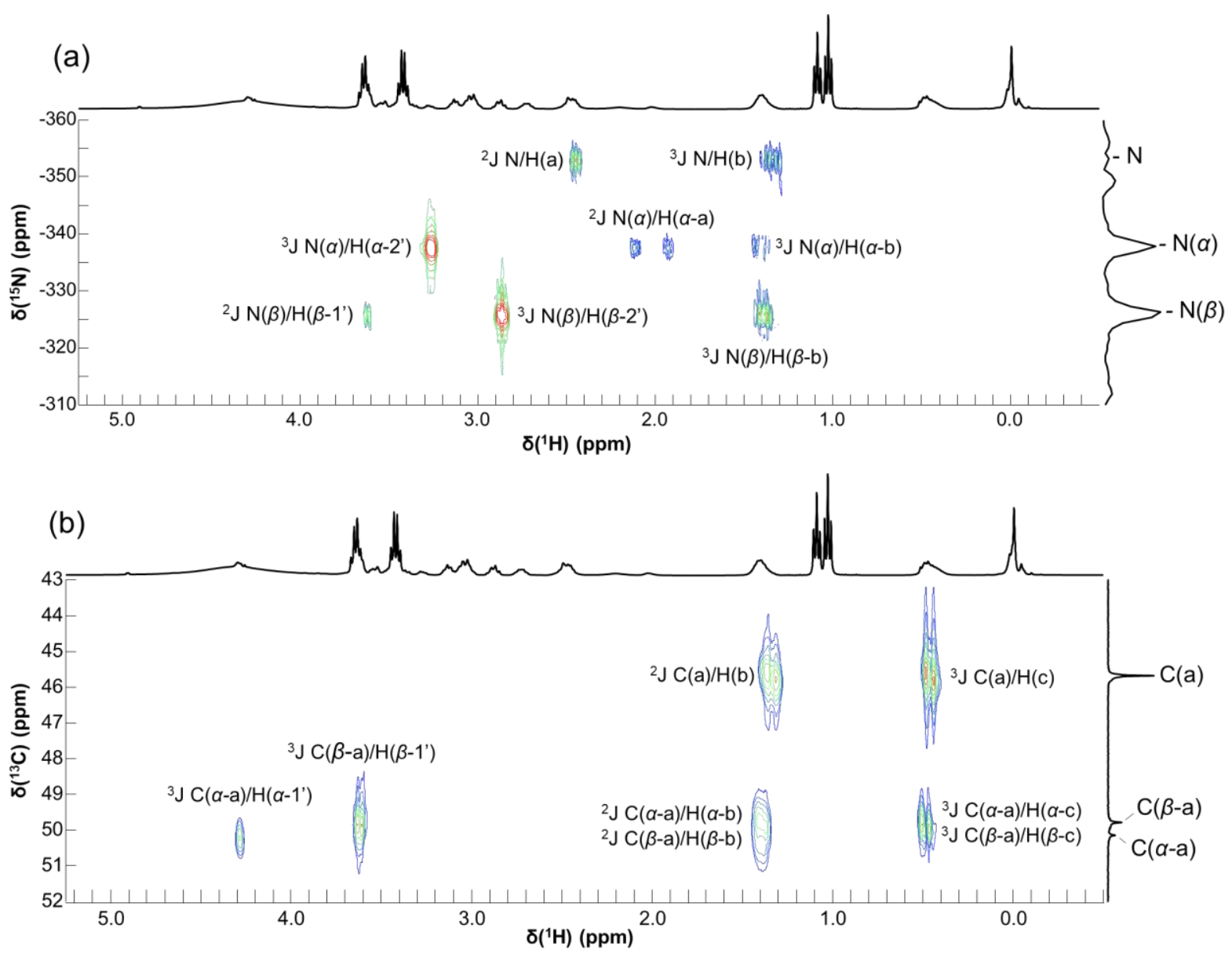

Figure 2. 2D NMR HMBC (a) ${ }^{1} \mathrm{H}_{-}-{ }^{15} \mathrm{~N}$ and (b) ${ }^{1} \mathrm{H}^{-13} \mathrm{C}$ spectra of $\mathrm{AM} / \mathrm{D}$-glucose (1/1) mixture. The hydrogens and carbons numbering is the same as in Figure 3. 
It has to be noted that there is no such thing as a perfect molecular model of cellulose, and D-glucose is no exception. Indeed, the reaction occurs with the hemiacetal functional group of D-glucose, which is present only in terminal $\mathrm{C}_{1}$ position (end-chain), i.e. under 1\%o considering an average DP of cellulose above 1000. Therefore, another model compound, MGPO (structure given in Figure S2b in the Supporting Information file) was used, which has a methoxy group in place of the $-\mathrm{OH}$ on $\mathrm{C}_{1}$ and thus better represents a mid-chain glucose. The formation of a terminal aldehyde group is thus not possible. The ${ }^{13} \mathrm{C}$ NMR spectrum of AM/MGPO 1/1 mixture shows that no reaction was observed in solution after several days, as expected (Figure S3 in the Supporting Information file). This result confirms the proposed reaction mechanism between AM and D-glucose, and points out that only the reducing-end anhydroglucose $C_{1}$ of cellulose would react with $A M$ in such way. As pointed out above, the average DP of cellulose being high, this indicates a very weak possible reactivity of the biopolymer. However, with a lower DP and branched chains, and hence a higher number of reactive sites, hemicelluloses are conceivably more reactive with AM. The same is true for degraded cellulose by acid catalyzed hydrolysis. ${ }^{29}$

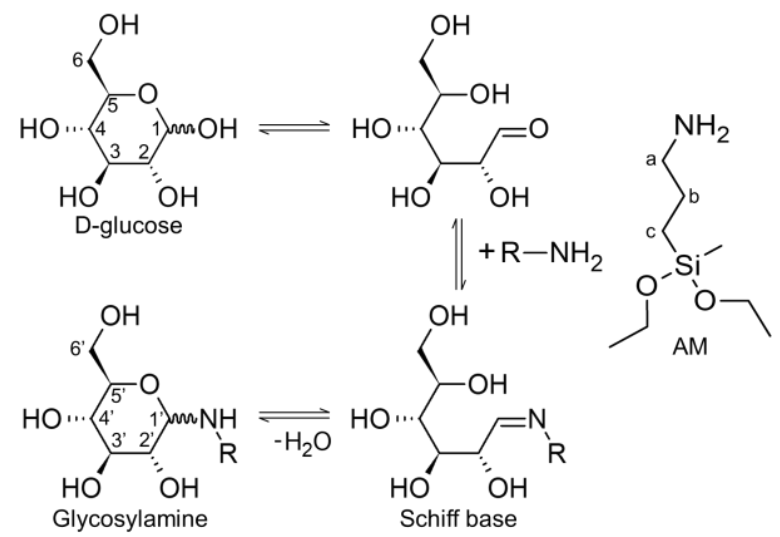

Figure 3. Maillard reaction between $\mathrm{AM}$ and $\mathrm{D}$-glucose. $\mathrm{R}^{-\mathrm{NH}_{2}}$ refers to $\mathrm{AM}$.

\subsection{Model lignin derivatives}

Lignin is another abundant biopolymer in mechanical pulp and unbleached pulp papers (i.e. $\mathrm{J} 2$ and J3). Lignin is a large polyphenol with a complex tridimensional amorphous structure, which builds a strong natural composite material with cellulose. ${ }^{29}$ Its structural units derive from three phenyl propane molecules, namely coniferyl, sinapyl and $p$-coumaryl alcohols, bound together by ether and carboncarbon bonds. ${ }^{29,31,34-37}$ In native softwood lignin, the structural elements are more than $95 \%$ coniferyl alcohol, ${ }^{38}$ which has only one methoxy group on the aromatic ring. The main monomer of grass lignin is coumaryl alcohol (no methoxy group), whereas hardwood lignin derives from sinapyl (two methoxy groups) and coniferyl alcohols. ${ }^{38}$

Lignins also contain other functional groups. In softwood lignin, the total number of hydroxyl groups lies between 1.3 and 1.5 per phenyl propane unit. ${ }^{37,38}$ It is estimated that there is only between 0.2 and 
0.3 phenol group per phenyl propane unit, ${ }^{34,37,38}$ thus aliphatic alcohols are predominant in the native biopolymer. There is about 0.2 carbonyl group per structural element of softwood lignin, $, 34,37,38$ whereas only a few percent carboxyl groups are present. ${ }^{38}$

Vanilloid molecules can be used as relevant structural models of lignin. Vanillin, vanillic acid and vanillyl alcohol were chosen in this work. The first two molecules are cited as common degradation products of lignin and are also found in paper. ${ }^{36,39-44}$ Natural aging of lignocellulosic paper also leads by oxidation to the formation of chromophore quinoid groups on the macromolecule. ${ }^{21,36}$ This was established as the main cause of yellowing of documents containing significant amounts of groundwood pulp. ${ }^{21}$ The reactivity of quinone structures was investigated here using $p$-benzoquinone.

3.3.1. Vanillin. The nitrogen signal of AM at -354 ppm totally disappeared on the $2 \mathrm{D}{ }^{1} \mathrm{H}-{ }^{15} \mathrm{~N} H M B C$ spectrum of the equimolar mixture AM/vanillin (Figure 4a), whereas a new and unique signal appears at $-61 \mathrm{ppm}$. This was attributed to the formation of an imine. A strong ${ }^{2} \mathrm{~J}$ coupling was observed between the nitrogen $\mathrm{N}$ and the hydrogen $\mathrm{H}(5)$ involved in the imine functional group (8.05-8.07 ppm). The $2 \mathrm{D}$ ${ }^{13} \mathrm{C}-{ }^{1} \mathrm{H}$ spectrum (Figure $4 \mathrm{~b}$ ) confirmed this assignment, as proved by the coupling between the same $\mathrm{H}(5)$ and the carbons $\mathrm{C}(2)$ (123.1 ppm), C(3) (127.3 ppm) and C(4) (109.9 ppm) of vanillin on the one hand, and $\mathrm{C}(6)$ (63.3 ppm) of $\mathrm{AM}$ on the other hand.

The FTIR spectrum of the equimolar mixture at $\mathrm{t}_{0}$ (Figure S4 in the Supporting Information file) corroborated the rapid formation of an imine. Whereas the intense peak at $1675 \mathrm{~cm}^{-1}$, characteristic of the conjugated $\mathrm{C}=\mathrm{O}$ group (stretching) disappeared, a new band appeared at $1642 \mathrm{~cm}^{-1}$, which indicates the production of a conjugated $\mathrm{C}=\mathrm{N}$ bond (stretching). ${ }^{27}$

This demonstrates that the amine of AM reacted with vanillin, yielding a Schiff base (Figure 4c). The instant yellowing of the vanillin white powder upon addition of AM is consistent with this reaction, as Schiff bases are notoriously yellow. In addition, the production of ethanol (signals at $1.06 \mathrm{ppm}$ and 3.44 ppm, Figure 4a) indicated a total hydrolysis of the ethoxy groups of AM (missing signals at $1.12 \mathrm{ppm}$ and $3.68 \mathrm{ppm}$ ). This is consistent with the formation of water occurring with the condensation reaction. The formation of the Schiff base was immediate and complete. 

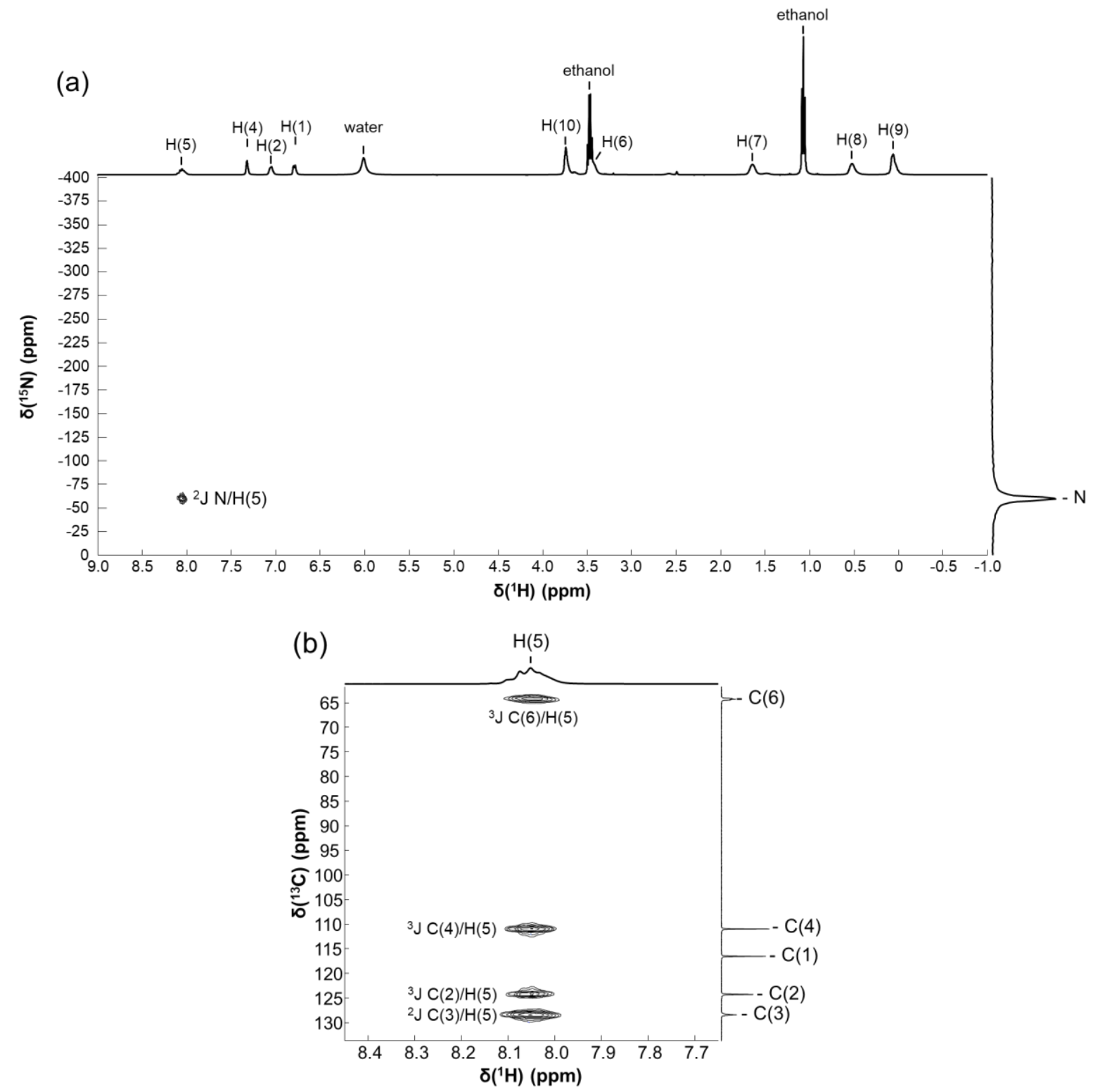

(c)

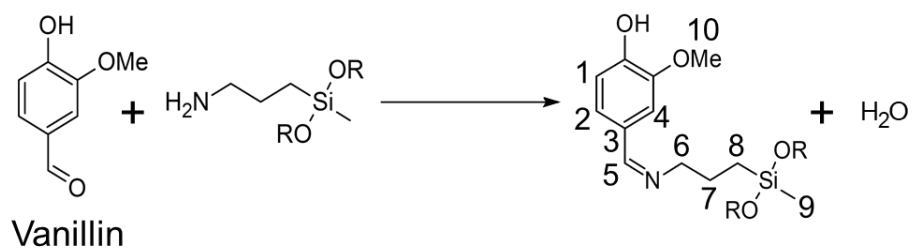

Figure 4. 2D NMR HMBC (a) ${ }^{1} \mathrm{H}-{ }^{15} \mathrm{~N}$, (b) ${ }^{1} \mathrm{H}^{-13} \mathrm{C}$ spectra of the $\mathrm{AM} /$ vanillin (1/1) mixture and (c) reaction between vanillin and $\mathrm{AM}$ : formation of a Schiff base. $\mathrm{R}$ refers to an ethyl group, a hydrogen or a polysiloxane chain.

Interestingly, the formation of water can favor the polymerization of AM. This hypothesis was confirmed as an equimolar mixture of $\mathrm{AM} / \mathrm{vanillin}$ without solvent quickly formed a gel. Besides, polycondensation reactions have been identified from the ${ }^{29} \mathrm{Si}$ NMR spectrum of the same mixture in DMSO- $d_{6}$ (Figure $5 \mathrm{~b}$ ). No $\mathrm{D}^{0}$ signal characteristic of AM monomer (Figure 5a) was detected at [-3; -7] 
ppm, which indicates the total reaction of the monomers to form polysiloxane chains. Signals $\mathrm{C}$ at [-13; -14] ppm and $\mathrm{E}$ at $[-21 ;-23] \mathrm{ppm}$ were associated to $\mathrm{D}^{1}$ (silicon atom bonded to one -O-Si group) and $\mathrm{D}^{2}$ (silicon atom bonded to two -O-Si groups), respectively (see Table 3 for more details). The numberaverage $\mathrm{DP}\left(\overline{\mathrm{DP}_{\mathrm{n}}}\right)$ of the linear chain estimated as $\overline{\mathrm{DP}_{\mathrm{n}}}=\left(\frac{2 \times D^{2}}{D^{1}}\right)+2$ was equal to 11 . The presence of the $\mathrm{D}^{2}$ signal $\mathrm{D}$ at $-19.3 \mathrm{ppm}$ on the same spectrum was attributed to the formation of a cyclic tetramer $\left(D^{2}\right)_{4}$, which occurs during the AM polycondensation. Every assignment of the ${ }^{29} \mathrm{Si}$ signals is consistent with the literature..$^{9,45,46}$

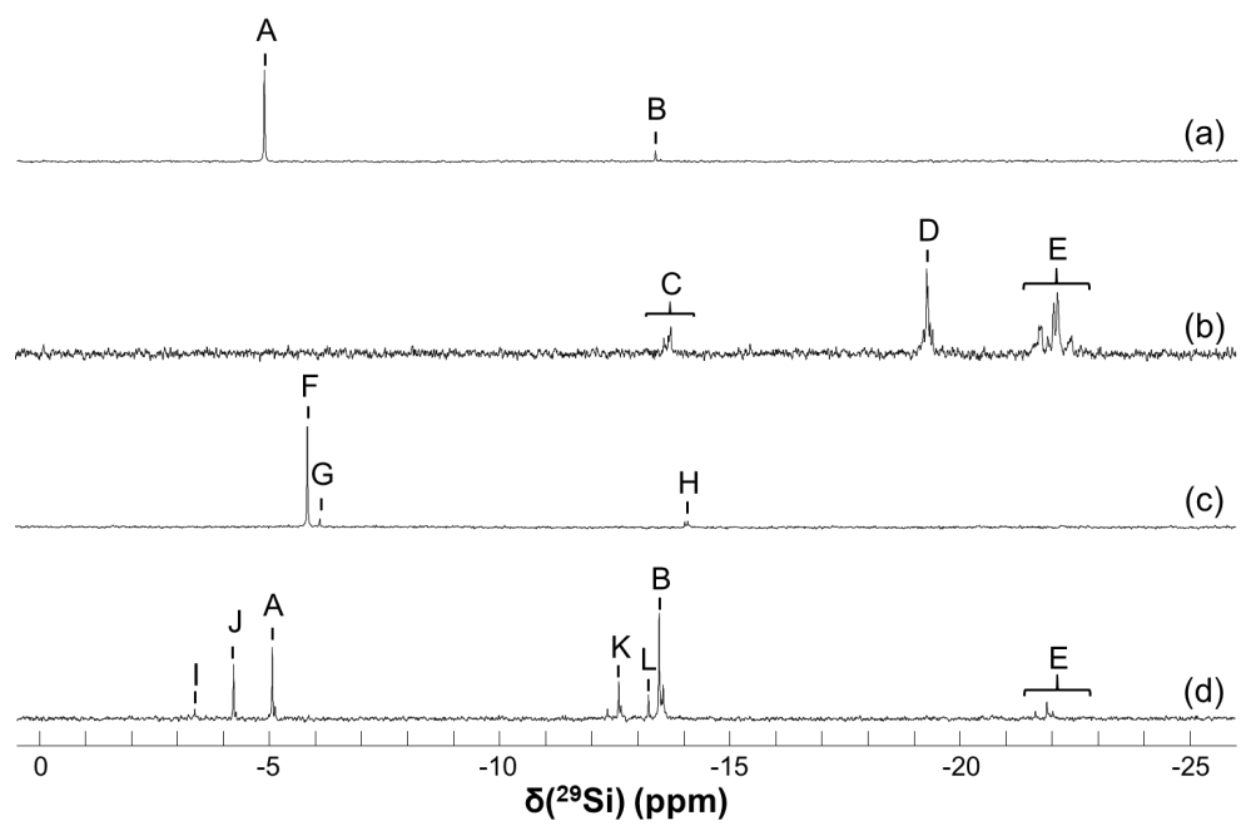

Figure 5. ${ }^{29} \mathrm{SiNMR}$ spectra of(a) AM, (b) AM/vanillin (1/1) mixture, (c) AM/vanillic acid (1/1) mixture, (d) AM/vanillyl alcohol (1/1) mixture. Assignments are in Table 3.

3.3.2. Vanillic acid. The $\mathrm{pK}_{\mathrm{A}}$ of amines are reported to be between 7 and 11 , whereas the $\mathrm{pK}_{\mathrm{A}}$ of vanillic acid is about 4.5 at $25{ }^{\circ} \mathrm{C} .{ }^{47} \mathrm{An}$ acid-base reaction between the two shall then proceed totally to form a salt. This was confirmed by the ${ }^{13} \mathrm{C}$ spectrum of the $\mathrm{AM} /$ vanillic acid (1/1) mixture (Figure $6 \mathrm{~b}$ ). For AM, the nearest carbons of the ammonium group formed, C(10) (28.3 ppm) and C(9) (46.2 ppm), moved upfield leading to signals at $22.8 \mathrm{ppm}$ and $42.9 \mathrm{ppm}$, respectively. The signals related to the farthest carbons C(11) (11.9 ppm), C(12) (-3.6 ppm), C(13) (58.6 ppm) and C(14) (19.5 ppm) remained at the same frequencies. Whereas $\mathrm{C}(8)$ of the $-\mathrm{OCH}_{3}$ group of vanillic acid presented the same chemical shift with and without AM (56.5 ppm), each of the signals corresponding to the carbon atoms of the conjugated system $(\mathrm{C}(2)$ to $\mathrm{C}(7)$ in the $[110 ; 180]$ ppm range in Figure 6$)$ showed frequency shifts. This is subsequent to the formation of a carboxylate involved in the molecule's conjugated system. 
Table 3. Assignments of the ${ }^{29} \mathrm{Si}$ NMR signals for AM, with and without a vanilloid (see Figure 5).

\begin{tabular}{|c|c|c|c|}
\hline${ }^{29} \mathrm{Si}$ NMR signal & $\delta(\mathrm{ppm})$ & Structure & Formula \\
\hline $\bar{A}$ & -4.9 & $\overline{\mathrm{D}_{(\mathrm{OEt})(\mathrm{OEt})}^{0}}$ & $(\mathrm{Me})\left(\mathrm{NH}_{2} \mathrm{C}_{3} \mathrm{H}_{6}\right) \mathrm{Si}(\mathrm{OEt})_{2}$ \\
\hline B & -13.4 & $\mathrm{D}_{(\mathrm{OEt})}^{1} \mathrm{D}_{(\mathrm{OEt})}^{1}$ & $(\mathrm{OEt})(\mathrm{Me})\left(\mathrm{NH}_{2} \mathrm{C}_{3} \mathrm{H}_{6}\right) \mathrm{SiOSi}\left(\mathrm{NH}_{2} \mathrm{C}_{3} \mathrm{H}_{6}\right)(\mathrm{Me})(\mathrm{OEt})$ \\
\hline $\mathrm{C}$ & {$[-13 ;-14]$} & $\mathrm{D}_{(\mathrm{OH})}^{1} \mathrm{D}^{2}$ & $(\mathrm{OH})(\mathrm{Me})\left(\mathrm{NH}_{2} \mathrm{C}_{3} \mathrm{H}_{6}\right) \mathrm{Si}-\mathrm{O}-\mathrm{S} \equiv$ \\
\hline $\mathrm{D}$ & -19.3 & $\left(D^{2}\right)_{4}$ & {$\left[(\mathrm{Me})\left(\mathrm{NH}_{2} \mathrm{C}_{3} \mathrm{H}_{6}\right) \mathrm{SiO}\right]_{4}$} \\
\hline $\mathrm{E}$ & {$[-21 ;-23]$} & $\mathrm{D}^{2}$ & $\equiv \mathrm{Si}-\mathrm{O}-(\mathrm{Me})\left(\mathrm{NH}_{2} \mathrm{C}_{3} \mathrm{H}_{6}\right) \mathrm{Si}-\mathrm{O}-\mathrm{S} \equiv$ \\
\hline $\mathrm{F}$ & -5.8 & $\mathrm{D}_{(\mathrm{OEt})(\mathrm{OEt})}^{0}$ & $(\mathrm{Me})\left(\mathrm{NH}_{3}{ }^{+} \mathrm{C}_{3} \mathrm{H}_{6}\right) \mathrm{Si}(\mathrm{OEt})_{2}$ \\
\hline G & -6.1 & $\mathrm{D}_{(\mathrm{OEt})(\mathrm{OH})}^{0}$ & $(\mathrm{Me})\left(\mathrm{NH}_{3}{ }^{+} \mathrm{C}_{3} \mathrm{H}_{6}\right) \mathrm{Si}(\mathrm{OEt})(\mathrm{OH})$ \\
\hline $\mathrm{H}$ & -14.1 & $\mathrm{D}_{(\mathrm{OEt})}^{1} \mathrm{D}_{(\mathrm{OEt})}^{1}$ & $(\mathrm{OEt})(\mathrm{Me})\left(\mathrm{NH}_{3}{ }^{+} \mathrm{C}_{3} \mathrm{H}_{6}\right) \mathrm{SiOSi}\left(\mathrm{NH}_{3}{ }^{+} \mathrm{C}_{3} \mathrm{H}_{6}\right)(\mathrm{Me})(\mathrm{OEt})$ \\
\hline I & -3.4 & $\mathrm{D}_{(\mathrm{AV})(\mathrm{AV})}^{0}$ & $(\mathrm{Me})\left(\mathrm{NH}_{2} \mathrm{C}_{3} \mathrm{H}_{6}\right) \mathrm{Si}(\mathrm{VA})_{2}$ \\
\hline $\mathrm{J}$ & -4.2 & $\mathrm{D}_{(\mathrm{AV})(\mathrm{OEt})}^{0}$ & $(\mathrm{Me})\left(\mathrm{NH}_{2} \mathrm{C}_{3} \mathrm{H}_{6}\right) \mathrm{Si}(\mathrm{VA})(\mathrm{OEt})$ \\
\hline K & -12.6 & $\mathrm{D}_{(\mathrm{AV})}^{1} \mathrm{D}_{(\mathrm{OEt})}^{1}$ & $(\mathrm{VA})(\mathrm{Me})\left(\mathrm{NH}_{2} \mathrm{C}_{3} \mathrm{H}_{6}\right) \mathrm{SiOSi}\left(\mathrm{NH}_{2} \mathrm{C}_{3} \mathrm{H}_{6}\right)(\mathrm{Me})(\mathrm{OEt})$ \\
\hline $\mathrm{L}$ & -13.2 & $\mathrm{D}_{(\mathrm{AV})}^{1} \mathrm{D}_{(\mathrm{OEt})}^{1}$ & $(\mathrm{VA})(\mathrm{Me})\left(\mathrm{NH}_{2} \mathrm{C}_{3} \mathrm{H}_{6}\right) \mathrm{SiOSi}\left(\mathrm{NH}_{2} \mathrm{C}_{3} \mathrm{H}_{6}\right)(\mathrm{Me})(\mathrm{OEt})$ \\
\hline
\end{tabular}

VA: substituted vanillyl alcohol. Solvent: DMSO- $d_{6}$.

In the ${ }^{29} \mathrm{Si} \mathrm{NMR}$ spectrum of the AM/vanillic acid mixture (Figure $5 \mathrm{c}$ ), the $\mathrm{D}^{0}$ signal $\mathrm{F}$ at $-5.8 \mathrm{ppm}$ corresponds to the protonated AM monomer, and can be compared to the signal A of the reference AM (Figure 5a). The $\mathrm{D}^{1}$ signal $\mathrm{B}$ at $-13.4 \mathrm{ppm}$ was associated to the $\mathrm{AM}$ dimer naturally present in solution, which was identified from the absence of $\mathrm{D}^{2}$ peak relating to longer chains. The signal $\mathrm{H}$ at $-14.1 \mathrm{ppm}$ thus corresponded to the protonated dimer. The small $\mathrm{D}^{0}$ signal $\mathrm{G}$ at $-6.1 \mathrm{ppm}$ is noteworthy, and attributed to a partially hydrolyzed AM monomer (see Table 3 for more details), which indicated the presence of residual water. This highlights the formation of an ammonium salt.

On the FTIR spectrum of the mixture at $t_{0}$ (Figure $\mathrm{S} 5$ in the Supporting Information file), the peak at $1695 \mathrm{~cm}^{-1}$ assigned to the conjugated $\mathrm{C}=\mathrm{O}$ bond of the carboxylic acid (stretching) disappeared, whereas new bands appeared at 1544 and $1628 \mathrm{~cm}^{-1}$, which correspond to $\mathrm{C}=\mathrm{C}$ and $\mathrm{C}=\mathrm{O}$ in an aryl carboxylate, respectively. ${ }^{27}$ This confirmed the fast acid-base reaction between vanillic acid and AM.

To conclude, an immediate and total acid-base reaction occurred between AM and vanillic acid, yielding an ammonium salt (Figure 6d). These results were consistent with the intended use of AAAS to deacidify paper (Table 2). They also hinted at interactions that possibly occur between lignin and AM in the paper through ionic bonding. Amine functions, if they immediately interact with carboxylated degradation products (of lignin and possibly of cellulose too), would then not be available to form hydrogen bonding with cellulose fibers. The consequence would be less strengthening and a lower reserve of the treated paper. 


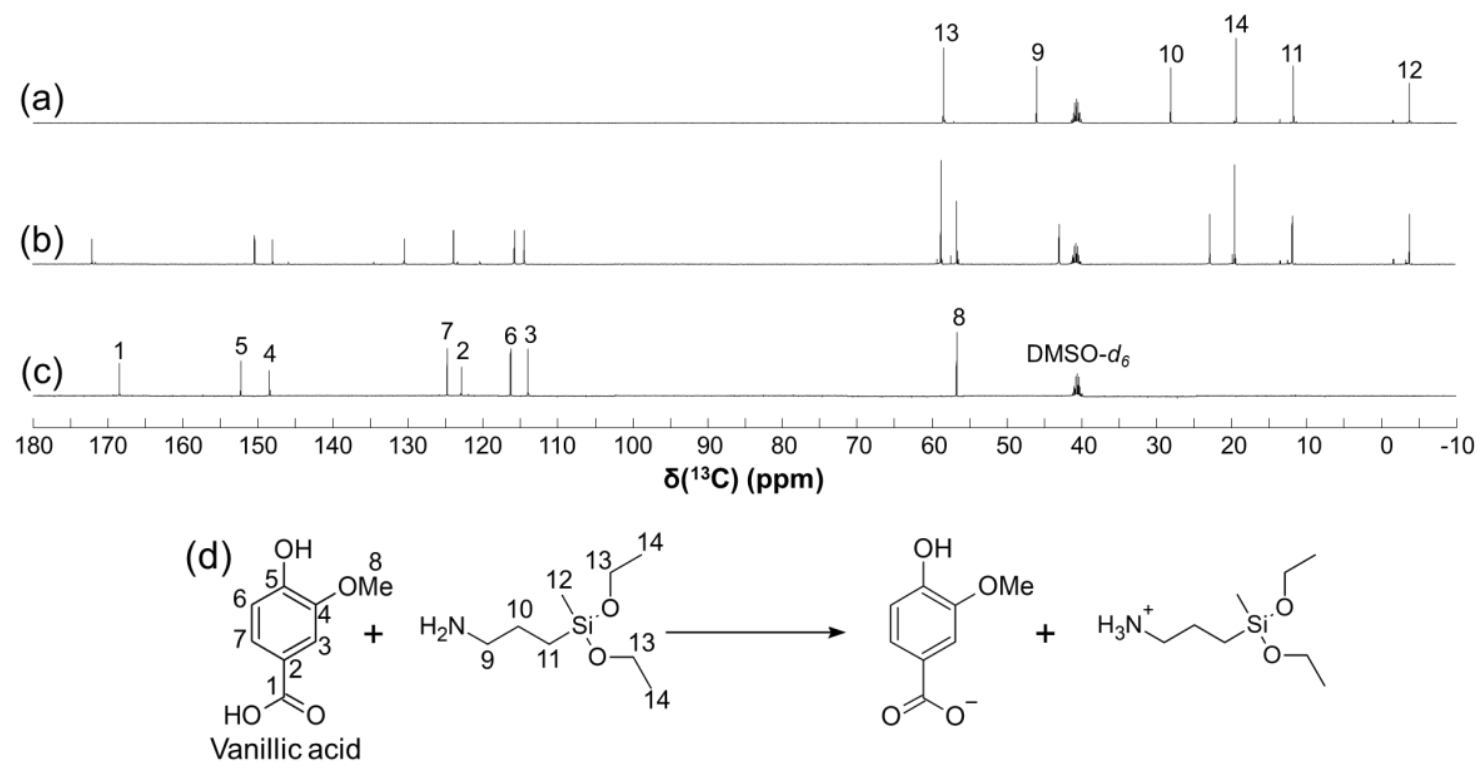

Figure 6. ${ }^{13} \mathrm{C}$ NMR spectra of (a) AM, (b) AM/vanillic acid (1/1) mixture, (c) vanillic acid, and (d) reaction between vanillic acid and AM: formation of an ammonium salt.

3.3.3. Vanillyl alcohol. The appearance of new peaks I (-3.4 ppm), J (-4.2 ppm), K (-12.6 ppm) and $\mathrm{L}(-13.2 \mathrm{ppm})$ on the ${ }^{29} \mathrm{Si}$ spectrum (Figure $5 \mathrm{~d}$ ) indicated condensation reactions taking place with the ethyl silicates. The hypothesis of hydrolysis of these functional groups was excluded since the DMSO$d_{6}$ used was fresh and totally anhydrous, and also because if so, the signals would have been detected at lower frequencies than signals $\mathrm{A}$ and $\mathrm{B}$ of $\mathrm{AM} .{ }^{48}$ The presence of peaks $\mathrm{A}$ and $\mathrm{B}$ on the spectrum indicated that a portion of AM did not react. With the noticeable exception of hydrogens $\mathrm{H}(*)$, corresponding to $\mathrm{H}(1)$ of the model molecule which partly reacted with $\mathrm{AM}$, no modification of the other signals' chemical shifts was noted on the ${ }^{1} \mathrm{H}$ spectrum of the mixture (Figure 7). The 2D HMBC ${ }^{1} \mathrm{H}-{ }^{29} \mathrm{Si}$ spectrum of the mixture (Figure 7) clearly indicated the ${ }^{3} \mathrm{~J}$ coupling between the silic on $\mathrm{Si}$ of AM and the hydrogen $\left.\mathrm{H}^{*}\right)$ of VA, which confirmed the condensation mechanism proposed. The $\mathrm{Si}(\mathrm{I}) / \mathrm{H}\left(^{*}\right)$ coupling corresponds to the AM monomer which has undergone two condensation reactions with vanillyl alcohol, whereas the $\mathrm{Si}(\mathrm{J}) / \mathrm{H}(*)$ coupling is associated to $\mathrm{AM}$ that has reacted only once. This assignment was confirmed by the presence of $\mathrm{a}^{3} \mathrm{~J}$ coupling between $\mathrm{H}(10)$ of the ethoxy group and $\mathrm{Si}(\mathrm{J})$, whereas it was absent for $\mathrm{Si}(\mathrm{I})$. The ${ }^{3} \mathrm{~J}$ coupling between $\mathrm{Si}(\mathrm{K})$ and $\mathrm{H}\left({ }^{*}\right)$ was attributed to the portion of AM dimers that reacted with vanillyl alcohol, since dimers were present in the commercial AM solution (signal B in Figure 5a). This also demonstrated that besides hydrolytic condensation, AM also underwent alcohol-driven condensation. Hence both water and alcohol are products of the AAAS polycondensation.

The study of vanillyl alcohol proved therefore that AM was able to react with other molecules, not only by the amine moiety, but also through the silicate groups. This work showed that AM can undergo successive esterification reactions with the primary aliphatic alcohol of the model molecule (Figure 7). Such transesterification reaction is seldom reported and requires specific reaction conditions. ${ }^{49}$ These 
reactions are limited despite the fact that condensation between alkoxysilanes and primary alcohols are catalyzed in alkaline conditions. ${ }^{45}$

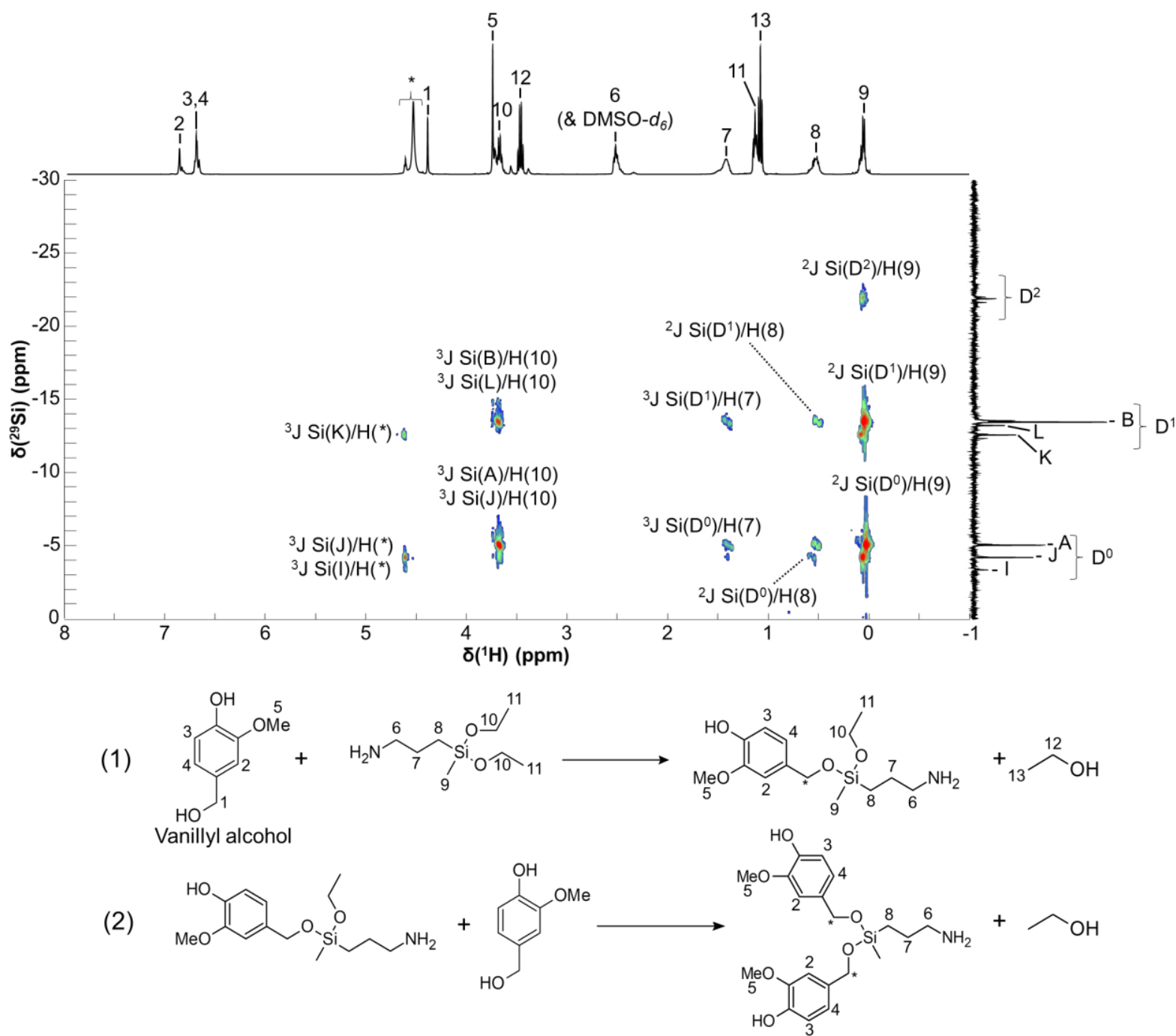

Figure 7. 2D NMR HMBC ${ }^{1} \mathrm{H}^{-29} \mathrm{Si}$ of the AM/vanillyl alcohol (1/1) mixture, and reaction between vanillyl alcohol and AM. (1) First esterification. (2) Second esterification. * corresponds to C1 of vanillyl alcohol condensed with AM. The silicon atoms numbering is the same as in Figure 5 and Table 3.

3.3.4. Cyclohexanol. AM/cyclohexanol (1/1) was studied by ${ }^{1} \mathrm{H}$ NMR in order to investigate the impact of steric hindrance on the kinetics of condensation reactions, since cyclohexanol is a secondary alcohol. No reaction was detected in solution after sevendays. It was thus assumed that the condensation reactions detailed above can take place mostly with the available primary aliphatic alcohols within lignin. Although they seem to be limited, and even more so in neutral conditions, it is essential to take these condensation reactions between AM and the lignin in paper into consideration, since they can ultimately result in limiting the polymerization of the AAAS thus leading to a low $\overline{\mathrm{DP}_{\mathrm{n}}}$. In situ, these 
reactions may compete with reactions between amines and carbonyls which, as seen previously, would have the opposite effect, namely increase the AM polycondensation.

3.3.5. p-benzoquinone. The ${ }^{1} \mathrm{H}$ NMR spectrum (Figure S6 in the Supporting Information file) showed a doublet at $6.529 \mathrm{ppm}$ and $6.525 \mathrm{ppm}$ and the absence of the peak associated with $p$-benzoquinone $(6.86$ ppm). These two peaks were attributed to two different products. AM reacted with $p$-benzoquinone according to the reaction in Figure $8{ }^{50,51}$ First, $\mathrm{AM}$ attached to a $\mathrm{C}=\mathrm{C}$ bond of the quinone, before the formation of a substituted hydroquinone by isomerization [step (1)]. The new product reacted immediately with the remaining $p$-benzoquinone through a redox reaction, yielding a free hydroquinone [step (2)]. AM reacted a second time with the other $\mathrm{C}=\mathrm{C}$ bond, leading to the twice-substituted final product upon new isomerization [step(3)]. This reaction was instant, total, exothermic, and also occurred in anhydrous conditions. The reaction mechanism was confirmed by FTIR. The spectrum at $t_{0}$ of the equimolar mixture $\mathrm{AM} / p$-benzoquinone where the nearly total absence of characteristic peaks in the spectral range 1600-1700 $\mathrm{cm}^{-1}$ indicated the formation of the phenol groups (Figure S7 in the Supporting Information file).<smiles>[R][R](C)(C)CCCNc1cc(O)ccc1O</smiles>

(2)

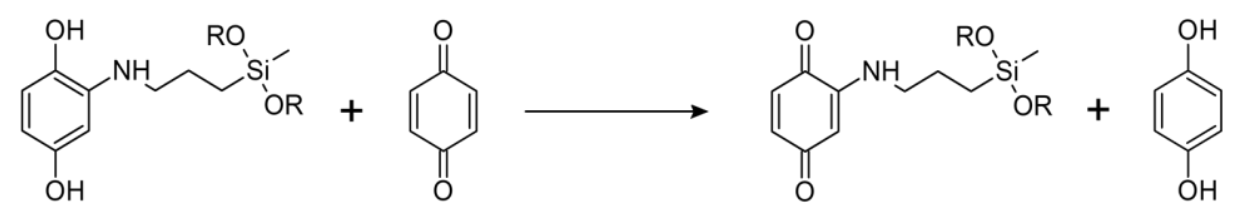

(3)

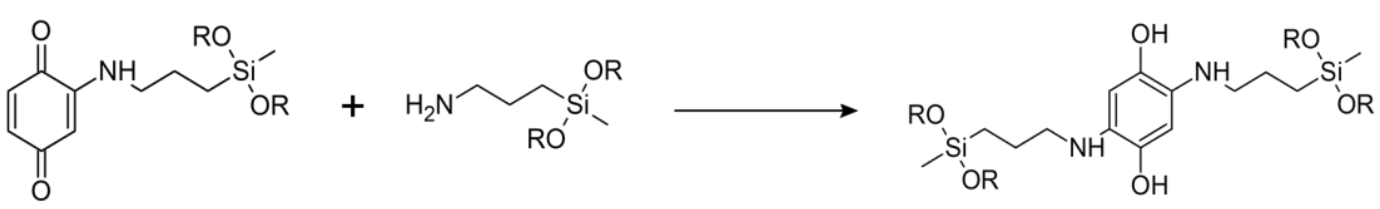

Figure 8. Reaction between AM and p-benzoquinone. (1) First electrophile addition of AM and isomerization. (2) Redox reaction with the remaining $p$-benzoquinone. (3) Second electrophile addition of $\mathrm{AM}$ and isomerization.

Evidencing this reaction demonstrated once more the ability of the amine groups of AM monomers to very quickly react and form covalent bonds with lignin and its degradation products. The amount of quinones arising from oxidized lignin in degraded papers can be substantial. However, this reaction mechanism can only occur with unsubstituted $\mathrm{CH}=\mathrm{CH}$ bonds, which drastically reduces the number of available reactive sites. Aromatic groups of softwood lignin are rich in methoxy groups, the main precursor being coniferyl alcohol, as previously described. 
3.3.6. Other models. Three other models of lignin, namely mequinol, phenol and anisole, and their reactivity with AM were studied because of the analogy to two other important functional groups in lignin: ether (methoxy group directly bonded to an aryl group) and phenol groups. No reaction was observed after 7 days in DMSO- $d_{6}$. These two functional groups are most probably unreactive with AM.

\subsection{Extrapolation to the mechanical properties of paper}

As demonstrated, based on the modelling study, lignin and its degradation products can in all likelihood react with AM. Assuming that other AAAS, such as AP and DIA, have a similar reactivity than AM, the side reactions identified could occur when treating lignocellulosic papers with these compounds, and thus affect the strengthening efficiency. It is noteworthy that newsprint $\mathrm{J} 2$ is more brittle than $\mathrm{J} 3$ (Figure 1), and has a lower $\mathrm{pH}$ (Table 2). It is thus proposed that the numerous acidic and oxidized functions and degradation products of lignin in $\mathrm{J} 2$ reacted rapidly with the AAAS. This in turn could impact the mechanical reinforcement of $\mathrm{J} 2$ either by hindering hydrogen bonds formation or by limiting the polycondensation reaction. Both are assumed to be key parameters to the strengthening. This could explain why the treatment was more efficient on the less degraded (and most likely less oxidized) lignocellulosic paper J3. Lastly, as J1 is as brittle as J2, but does not contain lignin, the absence of lignin could explain why its strengthening was more efficient.

\section{Conclusion}

The investigation using NMR enabled a better understanding of the reaction mechanisms that can occur between AM and key biopolymers of paper, namely cellulose (and indirectly hemicelluloses) and lignin. Cellulose being barely reactive towards AM, it seems that in order to effect strengthening, the interaction between AAAS and cellulose is mostly done through hydrogen bonds. In contrast, several characteristic and abundant functional groups of lignin were found very reactive, in particular the oxidized ones, such as aldehyde, ketone and quinone moieties, but also the numerous accessible aliphatic alcohols in the polyphenol. The reactions involving the amine moiety of AAAS modify the extent of the alkaline reserve, in addition to slowing the polycondensation. In the future, in situ analysis of treated papers will be carried out with solid-state NMR spectroscopy. This hopefully will allow corroborating the present work conclusions. The disparities in the treatment efficiency depending on the papers constituents will be more easily understood, with the aim to optimizing the treatment formulation. 


\section{Acknowledgments}

This work was supported by the Paris Seine Graduate School Humanities, Creation, Heritage, Investissements d'Avenir ANR-17-EURE-0021 - Foundation for Cultural Heritage Science, and by ANR-11-LABX-0039-grant (Labex CHARMMMAT). The participation of the Bibliothèque Nationale de France is acknowledged. Camille Piovesan, Alice Gimat, Oulfa Belhadj and Sabrina Paris-Lacombe (CRC), Isabelle Fabre-Francke (LPPI), Gérard Mortha (Grenoble INP - Pagora), Hervé Cheradame (Polytheragene) and Nathalie Steunou (Institut Lavoisier de Versailles) are warmly thanked for technical contribution and fruitful discussions.

\section{References}

(1) Baty, J. W.; Maitland, C. L.; Minter, W.; Hubbe, M. A.; Jordan-Mowery, S. K. Deacidification for the Conservation and Preservation of Paper-Based Works: A Review. BioResources 2010, 5 (3), 1955-2023.

(2) Carter, H. A. The Chemistry of Paper Preservation: Part 1. The Aging of Paper and Conservation Techniques. J. Chem. Educ. 1996, 73 (5), 417.

(3) Cheradame, H.; Ipert, S.; Rousset, E. Mass Deacidification of Paper and Books. I: Study of the Limitations of the Gas Phase Processes. Restaurator 2003, 24 (4), 227-239.

(4) Ahn, K.; Henniges, U.; Blüher, A.; Banik, G.; Potthast, A. Sustainability of Mass Deacidification. Part I: Concept, Selection of Sample Books and PH-Determination. Restaurator 2011, 32 (3), 193-222.

(5) Rousset, E.; Ipert, S.; Cheradame, H. Mass Deacidification of Paper and Books, II: Deacidification in the Liquid Phase Using Aminosilanes. Restaurator 2004, 25 (2), 104-118.

(6) Ipert, S.; Rousset, E.; Cheradame, H. Mass Deacidification of Papers and Books III: Study of a Paper Strengthening and Deacidification Process with Amino Alkyl Alkoxy Silanes. Restaurator 2005, 26 (4), 250-264.

(7) Ipert, S.; Dupont, A.-L.; Lavédrine, B.; Bégin, P.; Rousset, E.; Cheradame, H. Mass Deacidification of Papers and Books. IV-A Study of Papers Treated with Aminoalkylalkoxysilanes and Their Resistance to Ageing. Polymer Degradation and Stability 2006, 91 (12), 3448-3455.

(8) Dupont, A.-L.; Lavédrine, B.; Cheradame,H. Mass Deacidification and Reinforcement of Papers and Books VI-Study of Aminopropylmethyldiethoxysilane Treated Papers. Polymer Degradation and Stability 2010, 95 (12), 2300-2308.

(9) Souguir, Z.; Dupont, A.-L.; d'Espinose de Lacaillerie, J.-B.; Lavédrine, B.; Cheradame, H. Chemical and Physicochemical Investigation of an Aminoalkylalkoxysilane As Strengthening Agent for Cellulosic Materials. Biomacromolecules 2011, 12 (6), 2082-2091.

(10) Souguir, Z.; Dupont, A.-L.; Fatyeyeva, K.; Mortha, G.; Cheradame, H.; Ipert, S.; Lavédrine, B. Strengthening of Degraded Cellulosic Material Using a Diamine Alkylalkoxysilane. RSC Advances 2012, 2 (19), 7470.

(11) Piovesan, C.; Dupont, A.-L.; Fabre-Francke, I.; Fichet, O.; Lavédrine, B.; Cheradame, H. Paper Strengthening by Polyaminoalkylalkoxysilane Copolymer Networks Applied by Spray or Immersion: A Model Study. Cellulose 2014, 21 (1), 705-715.

(12) Rakotonirainy, M. S.; Dupont, A.-L.; Lavédrine, B.; Ipert, S.; Cheradame, H. Mass Deacidification of Papers and Books: V. Fungistatic Properties of Papers Treated with Aminoalkylalkoxysilanes. Journal of Cultural Heritage 2008, 9 (1), 54-59.

(13) Hubbe, M. A.; Smith, R. D.; Zou, X.; Katuscak, S.; Potthast, A.; Ahn, K. Deacidification of Acidic Books and Paper by Means of Non-Aqueous Dispersions of Alkaline Particles: A Review Focusing on Completeness of the Reaction. BioResources 2017, 12 (2). 
(14) Piovesan, C.; Fabre-Francke, I.; Paris-Lacombe, S.; Dupont, A.-L.; Fichet, O. Strengthening Naturally and Artificially Aged Paper Using Polyaminoalkylalkoxysilane Copolymer Networks. Cellulose 2018, 25 (10), 6071-6082.

(15) Piovesan, C.; Fabre-Francke, I.; Dupont, A.-L.; Fichet, O.; Paris-Lacombe, S.; Lavédrine, B.; Cheradame, H. The Impact of Paper Constituents on the Efficiency of Mechanical Strengthening by Polyaminoalkyla koxysilanes. Cellulose 2017, 24 (12), 5671-5684.

(16) Rankin, S. E.; McCormick, A. V. Hydrolysis Pseudoequilibrium: Challenges and Opportunities to Sol-Gel Silicate Kinetics. Chemical Engineering Science 2000, 55 (11), 1955-1967.

(17) de Monredon-Senani, S. Interaction Organosilanes/Silice de Précipitation Du Milieu HydroAlcoolique Au Milieu Aqueux. Laboratory of Condensed Matter Chemistry, Paris 6, 2004.

(18) Brochier Salon, M.-C.; Bayle, P.-A.; Abdelmouleh, M.; Boufi, S.; Belgacem, M. N. Kinetics of Hydrolysis and Self Condensation Reactions of Silanes by NMR Spectroscopy. Colloids and Surfaces A: Physicochemical and Engineering Aspects 2008, 312 (2), 83-91.

(19) Hüsing, N.; Schubert, U.; Mezei, R.; Fratzl, P.; Riegel, B.; Kiefer, W.; Kohler, D.; Mader, W. Formation and Structure of Gel Networks from $\mathrm{Si}(\mathrm{OEt}) 4 /(\mathrm{MeO}) 3 \mathrm{Si}(\mathrm{CH} 2) 3 \mathrm{NR}$ '2 Mixtures $(\mathrm{NR}$ ' $2=\mathrm{NH} 2$ or NHCH2CH2NH2). Chem. Mater. 1999, 11 (2), 451-457.

(20) Smook, G. A. Handbook for Pulp \& Paper Technologists; Tappi Pr: Vancouver; Bellingham, 2002.

(21) Carter, H. A. The Chemistry of Paper Preservation: Part 2. The Yellowing of Paper and Conservation Bleaching. J. Chem. Educ. 1996, 73 (11), 1068.

(22) Potthast, A.; Kostic, M.; Schiehser, S.; Kosma, P.; Rosenau, T. Studies on Oxidative Modifications of Cellulose in the Periodate System: Molecular Weight Distribution and Carbonyl Group Profiles. Holzforschung 2007, 61 (6)

(23) Isenberg, I. H. Pulp and Paper Microscopy; Institute of Paper Chemistry, 1967.

(24) Browning, B. L. Analysis of Paper, Enlarged 2nd edition.; M. Dekker: New York, 1977.

(25) Derrick, M. R.; Stulik, D.; Landry, J. M. Infrared Spectroscopy in Conservation Science; Getty Conservation Institute: Los Angeles, 1999.

(26) Calvini, P.; Gorassini, A. FTIR - Deconvolution Spectra of Paper Documents. Restaurator 2002, 23, 48-66.

(27) Socrates, G. Infrared and Raman Characteristic Group Frequencies: Tables and Charts, 3rd Edition.; Wiley-Blackwell: Chichester, 2004.

(28) Zhou, X.; Broadbelt, L. J.; Vinu, R. Mechanistic Understanding of Thermochemical Conversion of Polymers and Lignocellulosic Biomass. In Advancesin Chemical Engineering; Elsevier, 2016; Vol. 49, pp 95-198.

(29) Area, M. C.; Cheradame, H. Paper Aging and Degradation: Recent Findings and Research Methods. BioResources 2011, 6 (4), 5307-5337-5337.

(30) Hon, D. N.-S.; Shiraishi, N. Wood and Cellulosic Chemistry, Second Edition, Revised, and Expanded, 2nd ed.; CRC Press: New York, 2000.

(31) Jones, D.; Ormondroyd, G. O.; Curling, S. F.; Popescu, C.-M.; Popescu, M.-C. Chemical Compositions of Natural Fibres. In Advanced High Strength Natural Fibre Composites in Construction; Elsevier, 2017; pp 23-58.

(32) Roberts, J. D.; Caserio, M. C. Basic Principles of Organic Chemistry, 2nd Revised edition edition.; Imprint unknown: Menlo Park etc., 1977.

(33) Shendurse, A. M.; Khedkar, C. D. Glucose: Properties and Analysis. In Encyclopedia of Food and Health; Elsevier, 2016; pp 239-247.

(34) Adler, E. Lignin Chemistry? Past, Present and Future. Wood Sci. Technol. 1977, 11 (3), 169-218.

(35) Methods in Lignin Chemistry; Lin, S. Y., Dence, C. W., Eds.; Timell, T. E., Series Ed.; Springer Series in Wood Science; Springer Berlin Heidelberg: Berlin, Heidelberg, 1992.

(36) Lignin and Lignans: Advances in Chemistry; Heitner, C., Dimmel, D., Schmidt, J. A., Eds.; Taylor \& Francis: Boca Raton, 2010.

(37) Sakakibara, A.; Sano, Y. Chemistry of Lignin. Wood and Cellulosic Chemistry 2001, 109-174.

(38) Brunow, G.; Lundquist, K. Functional Groups and Bonding Patterns in Lignin (Including the Lignin-Carbohydrate Complexes). In Lignin and Lignans: Advances in Chemistry;2010; pp 267299. 
(39) Tarabanko, V. E.; Tarabanko, N. Catalytic Oxidation of Lignins into the Aromatic Aldehydes: General Process Trends and Development Prospects. Int J Mol Sci 2017, 18 (11).

(40) Nevell, T. P.; Zeronian, S. Cellulose Chemistry and Its Applications; Prentice Hall, 1985.

(41) Strlič, M.; Kralj Cigić, I.; Možir, A.; de Bruin, G.; Kolar, J.; Cassar, M. The Effect of Volatile Organic Compounds and Hypoxia on Paper Degradation. Polymer Degradation and Stability 2011, 96 (4), 608-615.

(42) Dupont, A.; Egasse, C.; Morin, A.; Vasseur, F. Comprehensive Characterisation of Celluloseand Lignocellulose-Degradation Products in Aged Papers: Capillary Zone Electrophoresis of Low-Molar Mass Organic Acids, Carbohydrates, and Aromatic Lignin Derivatives. Carbohydrate Polymers 2007, 68 (1), 1-16.

(43) Dupont, A.-L.; Seemann, A.; Lavédrine, B. Capillary Electrophoresis with Electrospray Ionisation-Mass Spectrometry for the Characterisation of Degradation Products in Aged Papers. Talanta 2012, 89, 301-309.

(44) Shahani, C. J.; Harrison, G. Spontaneous Formation of Acids in the Natural Aging of Paper. Studies in Conservation 2002, 47 (sup3), 189-192.

(45) Bennevault-Celton, V.; Maciejak, O.; Desmazières, B.; Cheradame, H. Condensation of Alkoxysilanes in Alcoholic Media: II. Oligomerization of Aminopropylmethyldiethoxysilane and Co-Oligomerization with Dimethyldiethoxysilane. Polymer International 2010, 59 (9), 1273-1281.

(46) Pellizzi, E.; Lattuati-Derieux, A.; de Lacaillerie, J.-B. d'Espinose; Lavédrine, B.; Cheradame, H. Reinforcement Properties of 3-Aminopropylmethyldiethoxysilane and N-(2-Aminoethyl)-3Aminopropylmethyldimethoxysilane on Polyurethane Ester Foam. Polymer Degradation and Stability 2012, 97 (11), 2340-2346.

(47) Vanillic acid https $/ /$ www.drugbank.ca/drugs/DB02130 (accessed Jun 8, 2019).

(48) Sugahara, Y.; Okada, S.; Kuroda, K.; Kato, C. 29Si-NMR Study of Hydrolysis and Initial Polycondensation Processes of Organoalkoxysilanes. I. Dimethyldiethoxysilane. JournalofNonCrystalline Solids 1992, 139, 25-34.

(49) Dakhili, S. Y. T.; Caslin, S. A.; Faponle, A. S.; Quayle, P.; Visser, S. P. de; Wong, L. S. Recombinant Silicateins as Model Biocatalysts in Organosiloxane Chemistry. PNAS 2017, 114 (27), E5285-E5291.

(50) Morrison, M.; Steele, W.; Danner, D. J. The Reaction of Benzoquinone with Amines and Proteins. Archives of Biochemistry and Biophysics 1969, 134 (2), 515-523.

(51) Kutyrev, A. A. Nucleophilic Reactions of Quinones. Tetrahedron 1991, 47 (38), 8043-8065. 